\title{
10. LA MÍMESIS DEL DESEO Y LA VIOLENCIA RELIGIOSA EN RENÉ GIRARD: LECTURA DESDE LA HERMENÉUTICA ANALÓGICA
}

\section{INTRODUCCIÓN}

René Girard se ha hecho célebre por su tesis del deseo de mímesis del otro como base de las relaciones sociales, mímesis que ayuda a identificarse como persona, y a desear al otro, pero también a odiarlo y verlo como rival. La mímesis es una idea muy antigua, a veces, vista solo desde su lado bueno, pero que también requiere ser visualizada desde su lado malo. Y la mímesis o imitación es apropiarse del otro, asimilarse a él, serle semejante, hacerse un análogo. Por lo tanto, aquí está presente la noción de analogía, que acompaña a la mímesis griega. Y, por eso, una visión de la mímesis desiderativa de Girard desde la hermenéutica analógica puede esclarecernos algunas cosas, algunos aspectos de ella. En todo caso, la mímesis nunca es unívoca, pero tampoco equívoca, tiene que ser analógica, y para encontrar ese punto medio nos puede valer una hermenéutica analógica, que ponga en equilibrio el lado bueno y el lado malo de la imitación de los demás.

\section{VIDA Y OBRA DE RENÉ GIRARD}

Nació en 1923 en Aviñón. Allí estudió filosofía y se graduó en 1941. De 1943 a 1947 estudió en la École des Chartes, de París, Historia Medieval. En 1947 fue a la Universidad de Indiana y en ella se 
doctoró en Historia en 1950 y allí permaneció hasta 1953. Enseñó en la Universidad de Duke, en el Bryn Mawr College, la Universidad John Hopkins, SUNY en Buffalo y en la Universidad de Stanford, donde se jubiló en 1995.

Obras: Mensonge romantique et vérité romanesque (1961); Proust: A collection of critical essays (1962); Dostoievski: du double à l'unité (1963); La violence et le sacré (1972); Critique dans un souterrain (1976); Des choses cachées depuis la fondation du monde (1978); To double business bound: Essays on literatura, mimesis, and anthropology (1978); Le bouc émissaire (1982); La Route antique des hommes pervers (1985); A theater of envy. $W$. Shakespeare (1991); Quand ces choses commenceront (1994); Je vois Satan tomber comme l'éclair (1999); Celui par qui le scandale arrive (2001); La Voix méconnue du réel: Une théorie des mythes archaïques et moderns (2002); Le sacrifice (2003); Dieu, une invention? (2007); Anorexie et désir mimétique (2008); Mimesis and Theory (2008); La Conversión de l'art (2008).

\section{LA MÍMESIS DEL DESEO Y EL DESEO DE LA MÍMESIS}

Girard (1996, p. 24) tiene la idea de que en el hombre hay deseo, sobre todo, de ser. De ser con los demás, pero también desde los demás. Por ello, exhibe un instinto de imitación. Es la pulsión mimética. Dada la finitud y contingencia del ser humano, se complementa con los demás, busca relacionarse con ellos, y una de esas formas de relación es la de imitación o mímesis. Señala una especie de necesidad de imitar, es de alguna manera identificarse con el otro. Por eso, Girard coloca la mímesis en la perspectiva de un "deseo metafísico", a saber, de ser más, como una imitación rivalizadora. 
Esto nos recuerda la idea del espejo de Lacan (1981, pp. 11 y ss.). Él habla de una etapa del espejo, en la que el niño aprende a reconocerse e identificarse, pero también empieza a reflejarse en otros, como en un espejo. Por ejemplo, con otro niño que es su amigo, hasta tal punto que si el otro se enferma, él también se enferma. De esta manera, se ve el carácter mimético del ser humano, que necesita del otro para ser él mismo. En efecto, para identificarse, el hombre lo hace por contraste con los otros, los demás. Mimetizándose con ellos.

Es un deseo de ser según el otro, un deseo de identificarse totalmente con el otro (Lucia, 2010, p. 181). Eso denota que el ser humano es ontológicamente carente, incompleto y que necesita de los otros para realizarse. Es una mímesis, es tener al otro como modelo. $\mathrm{Al}$ imitar al otro en sus gestos, en sus acciones, en el tono de su voz, queremos asimilarlo a él todo, asimilar su ser.

Pero el otro, así como invita a imitarlo, así también impide la imitación. Es incitación y obstáculo al mismo tiempo, ya que no siempre es fácil imitarlo. A diferencia de Freud, Girard dice que nuestros deseos se configuran a partir de los deseos de los otros. Y, de modo parecido a Hegel, parece sostener que el ser humano, más que desear al otro, desea el deseo del otro, es decir, desea ser deseado por el otro (cosa que rescató Lacan).

Los griegos hablaron de la mímesis, pero no del deseo y la apropiación en relación con ella. Esto es lo que añade Girard. Los objetos se desean de acuerdo con la mediación de un modelo, es el mediador entre el deseante y el objeto de su deseo. De ello surge la mímesis de apropiación, del objeto, pero también trae conflicto, pugna; por eso, dejado el objeto, se pasa a la mímesis de antagonismo (con los rivales para obtener ese objeto) (1983, pp. 240 y ss.). Por eso, la mímesis no es solo positiva, también tiene una parte negativa, porque es divisiva y provocadora de conflicto. Mas, aunque 
provoca violencia, no es malo, pues, ayuda al deseo a elegir sus objetos a través de un mediador al que se imita como un modelo. En las comunidades primitivas, cuando había mucho conflicto, se buscaba un modelo para descargar sobre él la violencia, pero solía ser injustamente, por lo que era un chivo expiatorio; y la violencia casi siempre era sagrada, mediante mitos y ritos. Esta víctima propiciatoria pacificaba a todos. Luego se la sacralizaba (2003, pp. 130 y ss.). Esto sigue haciéndose en la actualidad, pero más veladamente.

Es decir, la mímesis violenta se volvería epidemia contagiosa para toda la sociedad si no se frenara con un sacrificio. Hay que echarle a alguien la culpa de querer apropiarse del carácter de modelo, de símbolo o signo imagen y, por eso, es llevado al castigo (muerte o destierro). La colectividad hace ver que esa víctima encarna todo el mal, y que cuando es asesinada o exiliada el orden se restablece en la sociedad.

\section{MÍMESIS Y VIOLENCIA (SAGRADA)}

Hay, según Girard, una triangulación entre el sujeto humano, el semejante o modelo y el objeto deseado. El objeto adquiere valor porque es deseado por el modelo, por lo tanto, se vuelve apetecible para el sujeto. Pero el sujeto no alcanza al modelo en ese símbolo de valor, con lo cual sufre humillación. Así, la admiración se vuelve odio, rivalidad trágica. Es un paradigma que ya se encuentra en los primates. La imitación conlleva la violencia colectiva.

El sociólogo Gabriel Tarde estudió esto en Las leyes de la imitación (1890), en relación con el ser humano. Ve que todas las relaciones sociales se dan en una ley natural, la de la imitación. Ella rige la constitución de la sociedad, en sus instituciones y valores. Es una ley 
repetitiva, casi pasiva o determinista. En cambio, Girard ve la imitación como un principio activo y recursivo: el otro es un rival porque es modelo y es modelo porque es rival. Guardan una oposición de tipo paradoja, una dialéctica que no se resuelve. Y la rivalidad genera resentimiento, por este motivo, lleva a la violencia.

Y cuando varios sujetos desean el mismo objeto, la violencia se contagia, e inunda toda la colectividad. Pues bien, en nuestra sociedad globalizada la rivalidad ha llegado a ser el modelo, todos llegan a ser rivales de todos. La competencia se ha vuelto categoría social. Y se puede cambiar a otro modelo, cada vez más inalcanzable, lo cual repercute en una insatisfacción que se torna algo ontológico del hombre.

Por lo pronto, esa mímesis violenta es algo característico de las instituciones sociales, por ello, la violencia es producida por la sociedad misma, como ley del más fuerte. Pero está oculta en el fondo social. La violencia construye el orden simbólico en la sociedad. Desde la marginación hasta la destrucción física proviene de la rivalidad, que en todo encuentra elementos impuros que hay que limpiar y traidores que hay que castigar. Así que todos somos perseguidores potenciales.

La envidia genera violencia, el odio es deseo de estar en el lugar del otro. Hay que matar al otro, ya sea físicamente o simbólicamente, con la difamación y la calumnia (2004, pp. 34). Esto, según Girard, es lo que cuentan los mitos antiguos, pero velándolo cuidadosamente: la envidia y el asesinato que provoca. Es la base de los ritos, de la religión y de la sociedad misma. A pesar de dos mil años de cristiandad, seguimos viviendo en ello. Hay siempre un asesinato originario, un homicidio fundador, el pecado original (p. 65). Desde Caín y Abel, pasando por Rómulo y Remo, hasta llegar a nuestros días. El chivo expiatorio es una víctima inocente, que se persigue hasta darle muerte. Se oculta la inocencia, se la disfraza 
de culpabilidad, por eso, conlleva la mentira. Es la comunidad la que quiere su muerte, pero lo esconde, diciendo que él es el que ha querido morir, el que ha clamado a gritos que lo maten, por su comportamiento diferente, extraño. El prójimo o próximo se vuelve extraño, extranjero o distante.

La comunidad toda participa en el odio de la víctima y en su sacrificio, y se lava las culpas pensando que las culpas se fueron con la víctima, como los "comedores de pecados" de la Edad Media. Todos se limpiaron de culpas, precisamente porque la víctima expiatoria los lavó con su sangre (real o simbólica). Surge, entonces, lo sacro, con su ambivalencia. Se consagra al que se sacrificó, se lo erige en modelo para ser mimetizado. Son los mitos, que hablan de dioses y de héroes como inicio de la historia. Y los ritos, que recomponen el orden social. Mitos y ritos que siguen hasta el día de hoy.

Solo que Girard encuentra algo diverso en el Nuevo Testamento. Satanás es el acusador de la víctima, en este caso Jesús, mientras que el Espíritu Santo, el Paráclito, el Espíritu de la verdad, es el que defiende su inocencia. Además, como ha sabido verlo Vattimo, Girard hace comprender que, mientras que anteriormente el dios pedía sacrificios, ahora es Dios quien se sacrifica, en Jesucristo. Según Girard, los Evangelios ofrecen una salida para evitar la violencia colectiva.

El proceso de superación del mecanismo victimario es, para Girard, el desarrollo o crecimiento en la humanidad, lo que nos aleja de la animalidad. Todavía estamos en camino, no se ha llegado a la meta; por eso, hay que favorecer esa marcha hacia la superación de la envidia y el odio. Se nos hace presente lo que decía Melanie Klein (1984, pp. 117 y ss.) acerca de las dos actitudes ante la vida: la envidia y la gratitud o gratuidad. El que solo ve rivales, envidia y no da; el que supera eso, es capaz de dar gratis, sin esperar recibir. 
Veo, sobre todo, una búsqueda muy particular en Girard: frenar el relativismo y el nihilismo actuales. Él los ve como fenómenos modernos, descendientes de la Ilustración. Pero tienen su origen en el carácter eminentemente competitivo del ser humano, que engendra violencia. Se dice que las verdades absolutas, las ideologías o metarrelatos son los que llevan a la violencia; pero igualmente o más llevan a ella los relativismos, porque son absolutos atomizados. Por ello, dice Girard:

No pienso que la proposición Amica veritas, sed magis amicus Plato sea en realidad muy diversa de su contraria. Para mí son la misma cosa. Diré por qué motivo no puedo ser un relativista. Pienso que el relativismo de nuestros días es el producto del fallo de la antropología moderna, de la tentativa de resolver los problemas ligados a la diversidad de las culturas humanas. La teoría mimética es un esfuerzo por demostrar que las diferencias culturales, por más significativas que sean en un determinado nivel, no lo son en otro. Existen miles de modalidades para codificar y regular la convivencia social, por ejemplo en relación con las leyes sobre el matrimonio, pero todas estas modalidades tienen, sin embargo, una finalidad común, la de prevenir los conflictos, y por ello de transformar a individuos que podrían odiarse en personas que, al contrario, son capaces de amarse mutuamente (2006, p. 30).

Con esto se ve que Girard no está de acuerdo con el relativismo de la verdad que el propio Vattimo sostiene.

El hombre es por esencia competitivo y, por ende, rival; desea ser mejor que el otro, y eso se ve en el trabajo intelectual, en la relación académica, en la iniciativa o empresa, etcétera. A eso Girard añade:

El nihilismo filosófico creo que nace del hecho de que nos damos cuenta de que nuestro lenguaje no concuerda con la realidad 
humana, que no alcanza a ser traducida en palabras; entonces se renuncia a explicarla aseverando que el problema no puede ser resuelto. No pienso que sea así. Yo creo que la actual forma de nihilismo es la falla de lo que llamamos iluminismo, de la visión racional elaborada en el siglo XVIII (pp. 42-43).

Sobre todo, por su insuficiencia para explicar las relaciones humanas, tan complejas, y que se quisieron simplificar demasiado.

Por lo tanto, me parece que Girard deja abierto un camino a la hermenéutica analógica, con la cual se puede tratar su idea de mímesis, porque desde la tradición clásica ella fue entendida como una imitación analógica, no como unívoca ni, mucho menos, equívoca. Y la mímesis de la que habla Girard, que ciertamente es distinta de la clásica, puede encontrar una realización analógica, no unívoca (en la que se da la frustración, porque es inalcanzable) ni equívoca (pues no es propiamente mímesis). Eso resalta del carácter analógico de una mímesis adecuada, que se aplica al ver el modelo como ícono, no como ídolo; de esta manera, se nos presenta una mímesis que no conduce al resentimiento y a la violencia por la frustración y el celo que desencadena en los imitadores, sino a una renuncia al resentimiento, al dejar de lado el celo, por tratarse de un hacerse análogo del otro, es decir, imitarlo solo analógicamente, con libertad y con predominio de la diferencia. A esta mímesis analógica pasaremos a continuación.

\section{MÍMESIS Y ANALOGÍA}

La mímesis tiene como objeto imitar a una persona, asemejarse al otro, para asimilárselo (entre los primitivos, incluso devorándolo). Y la persona que se imita deviene modelo. Y el modelo, imagen o símbolo tiene dos caras: de ícono y de ídolo (Beuchot, 1999a, pp. 
25 y ss.). Si bien es verdad que la educación tradicional solo vio el lado bueno de la mímesis (por ejemplo la imitación de Cristo) (véase mi introducción a T. de Kempis, La imitación de Cristo, 2000, pp. 5 y ss.), Girard resalta demasiado el lado malo. La imitación se da bien cuando el modelo es ícono para el que imita; se vuelve mala cuando el modelo es ídolo. Y eso depende tanto del que imita como del imitado. Muchas veces, el maestro no es ícono para el discípulo, sino ídolo. Es ídolo cuando le pide que lo adore, que es la condición de todo ídolo (todo ídolo pide ser adorado), con lo cual no conduce a lo que debe conducir en su carácter de símbolo. Pero es ícono cuando, en lugar de pedir que el que imita se quede en la admiración de él mismo, lo empuja hacia el verdadero destino de la simbolización, que es conducir a la Trascendencia.

Hay algo en lo que la analogía empieza a ayudarnos, y es a comprender la naturaleza y los límites de la mímesis: esta no es unívoca, tampoco equívoca, sino analógica. Ya entre los humanistas clásicos, del Renacimiento, se pensó que la mímesis no podía ser unívoca, esclavizadora, aunque tampoco equívoca, totalmente libre; tenía que ser analógica, es decir, ajustarse al modelo pero permitiendo que predominara la diferencia. Un ejemplo claro en esos tiempos renacentistas era Petrarca. Todos los poetas imitaban a Petrarca, desde Garcilaso y Boscán hasta Quevedo. Es muy significativo el título de la obra de Ignacio Navarrete, Los huérfanos de Petrarca (1997, pp. 298 y ss.), no solo porque eran llorones a más no poder en sus églogas, sino porque ya no podían revivir al padre simbólico, no lo tenían con presencia de univocidad, sino de analogía. Mera analogía, pero eso era suficiente. Es decir, todos lo imitaban, pero todos eran muy distintos. Igualmente, la imitación de Cristo era más bien una invitación que una imitación. Jamás se podría imitar a Jesús unívocamente, por supuesto que tampoco equívocamente, y se tenía que hacer analógicamente. 
Eso por lo que hace al aspecto positivo de la imitación. En cuanto a su lado negativo, que es el que señala Girard, también se aplica lo del ícono y el ídolo. Pero aquí se da más bien por parte del imitador, no del imitado. En efecto, el imitador endiosa al imitado, como el niño al padre y, entonces, lo ve como inalcanzable y, por eso, lo odia, lo ve como rival. Es bastante conocida la muerte del padre por los hermanos, que cuenta Freud.

Cuando la mímesis pretende ser unívoca, es decir, asimilarse al modelo hasta el punto de apropiárselo, eso lleva a la frustración y al resentimiento, por lo mismo, al odio, a la rivalidad con el inalcanzable. En ese caso, el modelo funciona como ídolo. Pero también el modelo puede funcionar como ícono, como algo que ayuda a ser asimilado y, entonces, conduce al ideal, y desinfla la rivalidad.

Melanie Klein se encarga de pintarnos lo horrible que es un mundo de puros rivales, en la competencia y competitividad que se desata hoy en día, y se requiere la actitud de gratuidad. No competir, sino compartir, colaborar como equipo, bajando la fuerza del individualismo narcisista.

La analogía se encarga de disminuir el afán de identificación, da conciencia de la diferencia, de que en toda mímesis predomina la diferencia. Pero también limita la diferencia, no la hace total. Esta limitación de la diferencia se ve en Girard cuando trata de frenar en algún punto el relativismo y el nihilismo que lo acompaña. En el volumen donde está su diálogo con Vattimo tiene un artículo intitulado "No solo interpretaciones, también hay hechos", que evidentemente se enfrenta al dictum de Nietzsche: "No hay hechos, solo interpretaciones". Trata de hacer ver que no puede haber solo interpretaciones, sin hechos a los que correspondan, porque así se suelta un relativismo sin fin. De hecho, señala que está en oposición 
a Vattimo (2010, pp. 21 y ss.), que es demasiado relativista, al dispensarse de la noción de verdad.

Una hermenéutica analógica trata de conservar la noción de verdad como correspondencia (de nuestras interpretaciones con los hechos), aunque no de manera biunívoca, porque la experiencia nos atestigua que eso es solo un ideal. Lo que suele ocurrir es que alcanzamos una adecuación proporcional, pero suficiente. Vattimo (20005, pp. 213 y ss.; Beuchot, 2006a, pp. 21 y ss.) me criticó este deseo de resguardar la verdad como adecuación o correspondencia. Por eso, creo estar más cerca de la perspectiva de Girard.

En ese sentido, Girard dice, en contra de las exageraciones de muchos posmodernos, que hay que confiar en la razón:

Antes de comenzar a sospechar que estas posibilidades interpretativas y de investigación estuviesen efectivamente a la mano, me interesaba, como muchos otros en torno mío en el contexto académico, a las varias modas intelectuales del momento, comprendidas aquellas más anti-referenciales, anti-lógicas y anti-científicas. [...] Sin ningún arrepentimiento, he renunciado a todos los juegos teóricos y he vuelto a las reglas de la evidencia y de la prueba más tradicionales y de sentido común. Sentía instintivamente, y siento aún, que la sola teoría que necesito es creer en la posibilidad de descubrir la verdad, creer en la existencia tanto de los hechos como de las interpretaciones (2006, p. 98).

Y concluye con una postura que podríamos legítimamente llamar analógica, proporcional, esto es, de equilibrio:

En la búsqueda del conocimiento, el último siglo y medio se ha caracterizado por excesos que se han movido en direcciones antitéticas. Primero se han dado las escuelas de pensamiento positivista, 
que han adorado los hechos sintiéndose tan fácil y constantemente en contacto con ellos hasta olvidar las interpretaciones. Este exceso ha sido seguido por la reacción opuesta, en principio legítima, pero que muy pronto ha conducido a excesos peores que los que debía rectificar. Buscamos por tanto renunciar a todas las pseudoradicalizaciones, tratando de fiarnos nuevamente de la razón sin idolatrarla. De ahora en adelante, buscamos creer tanto en los hechos como en las interpretaciones (2006, p. 98).

En estas palabras encontramos la negación de la idolatría, del ídolo, del modelo o paradigma como ídolo, de la verdad idolátrica, para buscar la verdad como ícono, como un análogo que conduce a la meta u objeto conveniente.

Por ello, conviene hacer una destrucción de la historia de la hermenéutica, así como Heidegger hacía una destrucción de la historia de la ontología. Quizá con ello la misma ontología no quedará tan destruida. Ya que hay que revisar por qué la hermenéutica reciente (de Nietzsche a Vattimo) ha querido acabar con la ontología, decretar el fin de la metafísica, poder decir: "El ser ha muerto", como Nietzsche dijo que Dios había muerto y Foucault que había muerto el hombre. Encontraríamos que se ha elegido a la ontología como el chivo expiatorio. Girard dice que se lo elige por las razones más arbitrarias, pero aquí se ven algunas razones claras de por qué la ontología ha sido elegida como víctima propiciatoria.

Se ha elegido como víctima a la ontología o metafísica porque quiso ser el saber más elevado a la vez que profundo. Eso lo declaró Heidegger varias veces, cuando todavía deseaba la metafísica (en Qué es metafísica, de 1929, en La esencia del fundamento, de ese mismo año, y en Introducción a la metafísica, curso de 1935). Ella servía de modelo y mediadora y, por eso, tuvo que ser rechazada, concitó el celo, la rivalidad y el odio, y fue desterrada y muerta. Se la hizo culpable, 
se la acusó de engendrar la ciencia y la técnica, y encima que había llevado a Auschwitz. Pero ella era inocente, sigue siéndolo, porque hay que distinguir la teoría del uso que se ha hecho de ella. Ella no conlleva el ethos que se le ha cargado. Se la ha cargado de culpas, que es lo que siempre se hace con el chivo expiatorio. Por lo tanto, se dice que ahora estamos en una época posmetafísica o posontológica. Eso es lo "políticamente correcto". Pero los que no nos fiamos de lo "políticamente correcto" deseamos la vuelta de la ontología o metafísica. No para idolatrarla, no para hacerla ídolo, que esto fue lo que la perdió, como en el caso de Heidegger, que llegó a idolatrarla, y después, como pasa con todo ídolo, la rompió, sino para que sea ícono, para que en verdad conduzca al ser, que es lo que debe hacer.

La analogía puede dar ese carácter icónico, no idólico, a la metafísica/ontología. Una ontología analógica, no unívoca, que fue la prepotente y monolítica, que atacan los posmodernos como la turba en busca de víctima, de la que habla Girard. Por supuesto que tampoco una ontología equívoca, que es la que han hecho los posmodernos que la han retenido, como ontología del presente (Foucault y Deleuze) o de la actualidad (Vattimo), pero que es demasiado débil. Se requiere una que sea débil, a diferencia de la unívoca, fuerte y violenta, pero no tan débil como la equívoca, relativista y también violenta, sino una que sea analógica, esto es, que, sin la pretensión idolátrica de la unívoca, no se diluya en la fragmentación de la equívoca, destruida por los que la envidian.

\section{CONCLUSIÓN}

En este diálogo con las posturas de René Girard hemos encontrado algunos resquicios que dan cabida a una hermenéutica analógica, como la que deseo sostener. La mímesis necesita ser analógica, no 
unívoca, porque eso conduce al celo, a la rivalidad, al resentimiento y a la violencia. Porque la mímesis unívoca es inalcanzable. Más bien, la analogía nos lleva a una mímesis en la que el modelo no es un ídolo, sino un ícono. Ambas son las dos caras de la analogía, pero una buena, el ícono, y otra mala, el ídolo. No en balde el ídolo es el que suele pedir adoración, lo que mueve al odio y, a la postre, desata la violencia. El ídolo es el resto del chivo expiatorio, el ícono es la presencia de la víctima salvadora, que regresa a la vida. 


\section{CONCLUSIONES}

Tras nuestro paso por los temas estudiados, nos queda la convicción de que la noción de analogía se imposta en la hermenéutica, como hermenéutica analógica tiene mucho que decir a la filosofía de la religión y a la teología actuales. Se entiende aquí la filosofía de la religión en el sentido que le da la filosofía analítica, que concuerda con lo que ahora se ve como teología fundamental y antes como apologética.

Lo vimos en santo Tomás de Aquino, que sistematiza la idea de la analogía en plena Edad Media, pero que sigue siendo estudiado, por las repercusiones que su filosofía del lenguaje tiene en la teología. Es un paradigma de la teología, sobre todo, de la que se hace en la Orden dominicana.

Igualmente, el Maestro Eckhart es otro paradigma de la teología universal, pero de manera especial de la dominicana. Supo conjuntar, de manera proporcional, la teología con la mística, a partir de lo que con igual justeza podemos llamar una hermenéutica analógica aplicada a la teología.

La apologética de Pascal es sumamente analógica, que se aleja del racionalismo unívoco de Descartes y del emotivismo obtuso de los fideístas a ultranza. Adopta una vía media para su concepción del hombre, y lo considera frágil, como una caña, pero con la dignidad altísima de una caña que piensa, nada menos. Por eso, le habla tanto 
desde la razón como desde el corazón, en una postura analógica que une esos dos extremos y concilia esos dos opuestos.

Ya, pasando a la hermenéutica, vemos que la analogía ocupa un lugar importante en los varios ámbitos en los que la interpretación se usa, en los que la hermenéutica encuentra aplicación. Tal es la hermenéutica analógica. Con el fin de que se comprenda mejor, me esfuerzo por trazar su desarrollo y los principales momentos de su construcción, para que se vean las aplicaciones suyas a diferentes campos, sobre todo, al de la filosofía de la religión y la teología.

Mas, dado que buscamos el entrecruce de la filosofía y la teología, hemos abordado la visión que de la religión tuvo Ludwig Wittgenstein, centrada en la mística. Una mística lógica. En ella no hace falta demostrar la existencia de Dios, pues, la creencia pertenece a nuestra educación y a nuestras experiencias, por lo que las pruebas salen sobrando. Se pretende, más bien, que la religión dé sentido a la vida, y que se muestre en la conducta, no tanto que se diga en el sistema teológico.

También abordamos algunos temas de la filosofía de la religión, que sirven a la teología fundamental. Preferí poner a un pensador no creyente (Walter Kaufmann) y a uno creyente (Leszek Kolakowski), para que se viera la coincidencia que en la actualidad se da más allá de la apologética racionalista, hacia una confluencia de la razón y la emoción, de la teología y la mística. Esto se ve en la polarización que hace Kaufmann entre la razón y la aspiración, la última de las cuales inclina a la religión. Y Kolakowski también deja de lado la razón frente a la religión y se atiene a la mística. En ambos se aprecia la presencia muy fuerte, en la actualidad, de la teología negativa, pero también la noción de analogía nos ha enseñado a salir de la teología meramente negativa pero sin caer en una teología puramente afirmativa o positiva. Fue lo que logró hacer santo Tomás de Aquino, precisamente ayudado por la noción de la analogía. 
Inclusive abordamos una línea de la teología, la teología de la liberación, que tuvo tanta importancia en América Latina, y que enfocamos desde la hermenéutica analógica, para darle un equilibrio prudencial, una ubicación que le corresponda hoy. Una hermenéutica analógica puede darle ese equilibrio proporcional o analógico, para que nos lleve a una utopía realizable o sustentable.

Igualmente, se presentaron algunas reflexiones sobre la idea de René Girard de la violencia de lo sagrado y su origen en el deseo mimético del hombre, esto es, de imitar a otros hombres, lo cual lleva a decepciones y resentimientos. Se vio que, si se enfoca desde una hermenéutica analógica, se llegará a ver al otro ser humano no como un rival, sino como un prójimo o próximo, un semejante o un análogo.

Se finaliza con algunas reflexiones sobre la labor teológica latinoamericana, a partir de ese producto suyo que fue la teología de la liberación, pero haciendo ver que si se plantea desde la hermenéutica analógica se lo hará de manera más adecuada, sobre todo, más acorde con el momento actual. Necesitamos en teología un realismo analógico, y esto puede alcanzarse con una hermenéutica del mismo tipo, es decir, en la línea de la analogía, dando cabida no solo al lado metonímico de la analogía de atribución y de la de proporcionalidad propia, sino al lado metafórico de la analogía de proporcionalidad impropia o metafórica, que puede llevarnos a la utopía, más allá de lo dado, que es muy decepcionante.

Todo esto nos hizo calibrar la importancia de la noción de analogía, tan vieja en la historia filosófico-teológica, pero, sobre todo, para impostarse en la teoría de la interpretación, en forma de hermenéutica analógica, la cual nos manifiesta su relevancia y actualidad. 



\section{BIBLIOGRAFÍA}

Alcalá, R. (2009, feb.-mar.). Los límites de la hermenéutica analógica. Multidisciplina, tercera época, 3, 103-106.

Beck, H. (1968). El ser como acto. Pamplona: Eunsa.

Bergson, H. (1990). Las dos fuentes de la moral y de la religión. México: Porrúa.

Beuchot, M. (1982). La vida y la doctrina del Maestro Eckhart. Cuadernos Dominicanos, 6, 1-30.

Beuchot, M. (1987a). Una semántica medieval del discurso religioso: la significación analógica en la escuela tomista. Acta Poetica, 8, 87-101.

Beuchot, M. (1987b). La analogía como instrumento lógico-semántico del discurso religioso. Analogía, 1(1), 5-13.

Beuchot, M. (1995a). Filología clásica y hermenéutica. En Cohen, E. (Ed.). Aproximaciones. Lecturas del texto (pp. 41-61). México: Universidad Nacional Autónoma de México.

Beuchot, M. (1995b). Tradición e innovación en hermenéutica. En AA. VV. Inter alia hermenentica. Memorias del seminario de hermenéutica y ciencias del espíritu (pp. 19-27). México: UNAM/ ENEP-Acatlán. 
Beuchot, M. (1996a). La hermenéutica y su fundamentación ontológica. En Efemerides Mexicana, 14(41), 219-229.

Beuchot, M. (1996b). La hermenéutica mística y metafísica del Maestro Eckhart. Divinitas, 39, 258-271.

Beuchot, M. (1997). Eugenio Trías y Hermes: límites, analogía y mestizaje. En Sanabria, J. R. y Beuchot, M. (Comps.). Algunas perspectivas de la filosofía actual en México (pp. 271-288). México: UIA.

Beuchot, M. (1999a). Las dos caras del símbolo: el icono y el ídolo. Madrid: Caparrós.

Beuchot, M. (1999b). El futuro de la filosofía. Fin de época. La filosofía ante el próximo milenio. Madrid: Residencia de EstudiantesConsejo Superior de Investigaciones Científicas.

Beuchot, M. (2000). Introducción a T. de Kempis. La imitación de Cristo (pp. 5-11). México: Jus.

Beuchot, M. (2001). La hermenéutica analógica en la filología. En Clark de Lara, B. y Curiel Defossé, F. (Coords.). Filología mexicana (pp. 619-637). México: UNAM.

Beuchot, M. (2002). La hermenéutica en la Edad Media. México: UNAM.

Beuchot, M. (2002). The Thomistic Anthropology of God's Image in History. Its Tradition and Actuality. En Rossi, M. M. y Rossi, T. (Eds.). Persona humana imago Dei et Christi in historia (vol. I, pp. 279-291). Atti del Congresso Internationale, Roma 6-8 de septiembre de 2000. Roma: Angelicum University Press. 
Beuchot, M. (2006a). Respuesta a G. Vattimo. En Beuchot, M.; Vattimo, G. y Velasco Gómez, A. Hermenéutica analógica y hermenéutica débil (pp. 51-55). México: UNAM.

Beuchot, M. (2006b). Respuesta a A. Velasco. En Beuchot, M.; Vattimo, G. y Velasco Gómez, A. Hermenéutica analógica y hermenéutica débil (pp. 55-58). México: UNAM.

Beuchot, M. (2007). El pensamiento analógico en Juan Carlos Scannone. En Stromata, LXIII(1-2), 179-188.

Beuchot, M. (2008a). Hermenéutica analógico-icónica y teología. Bogotá: Pontificia Universidad Javeriana-Facultad de Teología, Colección Teología Hoy, 67.

Beuchot, M. (2008b). Sobre la dialectización de la analogía. (Respuesta a Ortiz-Osés). En Analogía Filosófica, XXII(1), 191-196.

Beuchot, M. (2008c). La analogía, componente del pensamiento dominicano. Anámnesis, XVIII(2), 105-112.

Beuchot, M. (2009a). Hermenéutica, analogía y dialéctica para América Latina. Stromata, LXV(1-2), 75-83.

Beuchot, M. (2009b). Bartolomé de Las Casas. Su vida, obra y las influencias que recibió. Pensamiento Novohispano, 10, 13-24.

Beuchot, M. (2009c, feb.-mar.). Respuesta a Los límites de la hermenéutica analógica, de R. Alcalá. Multidisciplina, tercera época, 3, 107-109.

Beuchot, M. (2009d). Filosofía de la religión. México: Universidad Iberoamericana. 
Beuchot, M. (2009e). Tratado de hermenéutica analógica. Hacia un nuevo modelo de la interpretación (4a ${ }^{a}$ ed.). México: UNAM-Ítaca.

Beuchot, M. (2009f). Intento de respuesta a Jean Grondin. En Blanco Beledo, R. (Comp.). Hermenéutica analógica y crítica filosófica (pp. 36-41). México: Ed. Torres.

Beuchot, M. (2011). Perfiles esenciales de la hermenéutica. México: FCE.

Bianco, F. (2004). Introdurione a Gadamer. Bari: Laterza.

Blanco Beledo, R. (Comp.) (2009). Hermenéutica analógica y crítica filosófica. México: Ed. Torres.

Bochenski, I. M. (1948). On Analogy. The Thomist, 11, 474-497.

Bochenski, I. M. (1975). La lógica de la religión. Buenos Aires: Paidós.

Bochenski, I. M. (1989). Die fünf Wege. Freiburger Zeitschrift für Philosophie und Theologie, 36(3), 235-265.

Cabrera, I. y Silva, C. (Comps.) (2006). Umbrales de la mistica. México: UNAM.

Carraud, V. (1992). Pascal et la philosophie. París: PUF.

Casas, B. de Las (1989). Brevísima relación de la destrucción de Africa (estudio preliminar, edición y notas de I. Pérez Fernández). Salamanca-Lima: Editorial San Esteban-Instituto Bartolomé de Las Casas.

Deleuze, G. (1969). Nietzsche y la dialéctica. Eco, XIX(5-7), 605-619.

Descotes, D. (1993). L'argumentation chez Pascal. París: PUF. 
Díaz Núñez, L. G. (2009). Utopía y liberación en América Latina. La teología de la liberación. Desarrollos recientes (el desafío globalizador y posmoderno). México: UNAM.

Dussel, E. (1973). El método analéctico y la liberación latinoamericana. En Ardiles, R. et ál. Hacia una filosofía de la liberación latinoamericana (pp. 125-134). Buenos Aires: Bonum.

Dussel, E. (1982). Pensée analectique en philosophie de la libération. En Gisel, P. y Secretan, P. (Eds.). Analogie et dialectique. Essais de théologie fondamentale (pp. 93-120). Genève: Labor et Fides.

Dussel, E. (1992). Hermenéutica y liberación. De la "fenomenología hermenéutica" a una "filosofía de la liberación" (diálogo con Paul Ricoeur). Analogía Filosófica, VI(1), 141-181.

Dussel, E. (1996). La analogía de la palabra (el método analéctico y la filosofía latinoamericana). Analogía Filosófica, X(1), 29-60.

Eckhart, M. J. (1998). Tratados y sermones (selección e introducción de M. Beuchot). México: Consejo Nacional para la Cultura y las Artes. Colección Cien del Mundo.

Fernández Manzanedo, M. (1979). El hombre como microcosmos según santo Tomás. Angelicum, 56, 62 y ss.

Frost, E. C. (2002). La historia de Dios en las Indias. Visión franciscana del Nuevo Mundo. México: Tusquets.

Frost, E. C. (2004). Discurso de ingreso a la Academia Mexicana de la Lengua. México.

Gadamer, H.-G. (1997). Verdad y método. Fundamentos de una hermenéutica filosófica, Salamanca: Sígueme. 
Gambra, J. M. (2002). La analogía en general. Sintesis tomista de Santiago Ramirez: Pamplona: Eunsa.

Geertz, C. (1973). Thick Description: Toward an Interpretive Theory of Culture. En The Interpretation of Cultures (pp. 3 y ss.). Nueva York: Basic Books-Harper Torchbooks.

Geertz, C. (1991). Géneros confusos. La refiguración del pensamiento social. En Reynoso, C. (Comp.). El surgimiento de la antropología posmoderna (pp. 63 y ss.). México: Gedisa.

Girard, R. (1983). La violencia y lo sagrado. Barcelona: Anagrama.

Girard, R. (1996). Cuando comiencen a suceder estas cosas... Madrid: Encuentro.

Girard, R. (2003). La violenza e il mito. En Lotito, L. (Ed.). Il mito e la filosofia (pp. 130-133). Milán: Bruno Mondadori.

Girard, R. (2004). Il capro espiatorio. Milán: Adelphi.

Girard, R. (2006). Non solo interpretazioni, ci sono anche i fatti. En Girard, R. y Vattimo, G. Verità o fede debole? Dialogo su cristianesimo e relativismo (pp. 86-99). Massa: Transeuropa.

Girard, R. y Vattimo, G. (2006). Verità o fede debole? Dialogo su cristianesimo e relativismo (al cuidado de P. Antonello). Massa: Transeuropa.

Girau Reverter, J. (1995). Homo quodammodo omnia según santo Tomás de Aquino. Toledo: Estudio Teológico de San Ildefonso.

Gómez Caffarena, J. (1960). “Analogía del ser” y dialéctica en la afirmación humana de Dios. Pensamiento, 16(62), 143-173. 
Gómez Robledo, A. (1992). Estudios pascalianos. México: FCE.

Grabmann, M. (1946). La vida espiritual de santo Tomás de Aquino. Buenos Aires: Ed. Guadalupe.

Grondin, J. (2008). El camino analógico de Mauricio Beuchot. Estudios Filosóficos, 57, 521-531.

Haas, A. M. (2002). Maestro Eckhart. Figura normativa para la vida espiritual. Barcelona: Herder.

Hedwig, K. (2010). Analektik/Analéctica. Analogía Filosófica, XXIV(1), 3-32.

Heidegger, M. (1997). Estudios sobre mística medieval (2ª ed.). México: FCE.

Hernández de León Portilla, A. (2009). La hermenéutica de Sahagún y la creación de la antropología. En Hernández de León Portilla, A. (Coord.). Hermenéutica analógica. La analogía en la antropología y la bistoria (pp. 87-126). México: UNAM.

Hurtado Pérez, G. (2003). Introducción. En Hurtado Pérez, G. (Comp.). Hermenéutica analógica. Aproximaciones y elaboraciones (pp. 9-15). México: Ed. Ducere.

Hurtado Pérez, G. (2005). La crisis de mi ateísmo. Ixtus, XIII(54), 53-61.

Hurtado Pérez, G. (2010). Sospechar e interpretar. En Conde Gaxiola, N. (Coord.). En torno a la hermenéutica analógica (pp. 51-59). México: Ed. Torres.

Kaufmann, W. (1959, febrero). The Faith of a Heretic. En Harper's Magazine, pp. 33-39. 
Kaufmann, W. (1960). From Shakespeare to Existentialism (2a. ed.). Garden City, N. Y.: Doubleday-Anchor Books.

Kaufmann, W. (1965). Hegel. Madrid: Alianza.

Kaufmann, W. (1968). Editor's Introduction a F. Nietzsche. The Will to power (pp. xx-xxi). New York: Vintage Books.

Kaufmann, W. (1983). Crítica de la religión y la filosofía. México: FCE.

Klein, A. (1978). Meister Eckhart. La dottrina mistica della giustificazione. Milán: Mursia.

Klein, M. (1984). Envidia y gratitud. Emociones básicas del hombre (5ª ed.). Buenos Aires: Paidós.

Kolakowski, L. (1988). Si Dios no existe... Sobre Dios, el diablo, elpecado, y otras preocupaciones de la llamada filosofía de la religión. Madrid: Tecnos.

Kolakowski, L. (1990). La presencia del mito. Madrid: Cátedra.

Kolakowski, L. (1996). Dios no nos debe nada. Un breve comentario sobre la religión de Pascal y el espiritu del jansenismo. Barcelona: Herder.

Lacan, J. (1981). El estadio del espejo como formador de la función del yo tal como se nos revela en la experiencia psicoanalítica. En Escritos I (9a . ed.) (pp. 11-18). México: Siglo XXI.

Lakebrink, B. (1955). Hegels dialektische Ontologie und die thomistische Analektik. Köln: Bachem

Lakebrink, B. (1967). Hegels dialektische Ontologie und die thomistische Analektik. Freiburg i. Br.: Rombach. 
López Quintás, J. (1963). Metodología de lo suprasensible; descubrimiento de lo superobjetivo y crisis del objetivismo. Madrid: Editora Nacional.

Lucia, N. (2010). Il desiderio mimetico in René Girad. Sapienza, 63, 181-186.

Maccise, C. (1987). La teología de la liberación. 20 años de una praxis y reflexión teológico-pastoral. México: CEHVAC.

Moliner, J. M. (1974). Espiritualidad medieval. Burgos: Ed. El Monte Carmelo.

Murillo Gallegos, V. (2009). Palabras de evangelización, problemas de traducción. Fray Juan Bautista de Viseo y sus textos para confesores. Nueva España (siglo XVI), Zacatecas: UAZ.

Navarrete, I. (1997). Los huérfanos de Petrarca. Poesía y teoría en la Espana renacentista. Madrid: Gredos.

Ortiz-Osés, A. (2008). El enigma del ser. Analogía Filosófica. XXII(1), 185-190.

Panikkar, R. (1998). Iconos del misterio. La experiencia de Dios. Barcelona: Península.

Pascal, B. (1984). Pensamientos (trad. J. Domínguez Berrueta). Madrid: Sarpe.

Pascal, B. (1987). Del espíritu geométrico y del arte de persuadir (introd. y trad. M. Beuchot). Tetraktys, 3, 9-19.

Pascal, B. (1996). Ensayos, correspondencia y pensamientos. Barcelona: Ediciones 29.

Pears, D. (1973). Wittgenstein. Barcelona: Grijalbo. 
Peña, L. (1985). La dicotomía entre mostrar y decir y la noción de sentido en el Tractatus. En Estudios bumanísticos, 7, 145-170.

Puntel, B. (1969). Analogie und Geschichtlichkeit. Friburgo: Herder.

Reyes, G. (2009). Hermenéutica y analogía: hacia una epistemología analógica del texto narrativo bíblico. En Blanco Beledo, R. (Comp.). Hermenéutica analógica y crítica filosófica (pp. 7-20). México: Ed. Torres.

Ricoeur, P. (1982). Hermeneutics and the Human Sciences (ed. y trad. J. B. Thompson). Cambridge-París: Cambridge University PressÉditions de la Maison des Sciences de l'Homme.

Ricoeur, P. (1995). Tiempo y narración (3 vol.). México: Siglo XXI.

Ricoeur, P. (2003). Sí mismo como otro (2ª ed.). México: Siglo XXI.

Ricoeur, P. (2006). Caminos del reconocimiento. Tres estudios. México: FCE.

Ruiz Sotelo, M. (2010). Crítica de la razón imperial. La filosofía politica de Bartolomé de Las Casas. México: Siglo XXI.

Russell, B. (1969). My Philosophical Development. Londres: Allen and Unwin.

Sánchez Chamoso, R. (1982). La teoría bermenéutica de E. Schillebeeckx. Principios y criterios para la actualización de la tradición cristiana. Salamanca: Universidad Pontificia de Salamanca.

Saranyana, J. I. (1989). Meister Eckhart y la controversia coloniense (1326). A propósito de la libertad de investigación teológica. Scripta Theologica, XXI, fasc. 3, 887-902. 
Scannone, J. C. (1972). La liberación latinoamericana. Ontología del proceso auténticamente liberador. Stromata, 27, 107-150.

Scannone, J. C. (1999). Del símbolo a la práctica de la analogía. Stromata, 55, 19-51.

Scannone, J. C. (2003). Acontecimiento-sentido-acción. Aportaciones de Paul Ricoeur para una hermenéutica del acontecimiento y la acción histórica. Aplicación al acontecer argentino actual. Stromata, 59, 273-288.

Scannone, J. C. (2005). De más acá del símbolo a más allá de la práctica de la analogía. El lenguaje de la teología filosófica. En Religión y nuevo pensamiento. Hacia una filosofía de la religión para nuestro tiempo desde América Latina (pp. 187-224). Barcelona: Ánthropos.

Secretan, P. (1998). Analogía y trascendencia. Pascal-Edith SteinBlondel. Analogía, 3, número especial.

Secretan, P. y Gisel, P. (Eds.) (1962). Analogie et dialectique. Ginebra: Fides et Labor.

Strobl, W. (1963). Introducción a la filosofía de las ciencias. Madrid: Eds. Revista Estudios.

Swinburne, R. (2011). La existencia de Dios. Salamanca: Ed. San Esteban.

Tomás de Aquino, santo (1880). Adventus dominica secunda, sermo 1: De libro naturae. En Sermones et opuscula (ed. J. B. Raulx) (t. I, pp. 12-13). Verdún: Soc. S. Pauli.

Tomás de Aquino, santo (1955a). De veritate. En Opera. Taurini-Roma: Marietti. 
Tomás de Aquino, santo (1955b). Summa theologiae. En Opera. Taurini-Roma: Marietti.

Tomás de Aquino, santo (1955c). In II Sententiarum. En Opera. Taurini-Roma: Marietti.

Tomás de Aquino, santo (1955d). Contra gentiles. En Opera. Taurini-Roma: Marietti.

Tomás de Aquino, santo (1955e). In III De anima. En Opera. Taurini-Roma: Marietti.

Tomás de Aquino, santo (1955f). Compendium theologiae. En Opera. Taurini-Roma: Marietti.

Tomasini Bassols, A. (1988). Elpensamiento del último Wittgenstein. Problemas de filosofía contemporánea. México: Trillas.

Tomasini Bassols, A. (2011). Explicando el Tractatus. Una introducción a la primera filosofía de Wittgenstein. Buenos Aires: Gramma.

Torrell, J.-P. (1998). Tommaso d'Aquino, maestro spirituale. Roma: Città Nuova Ed.

Vattimo, G. (2005). ¿Hermenéutica analógica o hermenéutica anagógica? Estudios Filosóficos, LIV(156), 213-227.

Vattimo, G. (2010). Adiós a la verdad. Barcelona: Gedisa.

Velasco Gómez, A. (2006). Hermenéutica analógica y heurística. Sobre un diálogo sin consenso pero muy edificante. En Beuchot, M.; Vattimo, G. y Velasco Gómez, A. Hermenéutica analógica y hermenéutica débil (pp. 43-50). México: UNAM. 
Villar Ezcurra, A. (1987). Pascal: ciencia y creencia. Madrid: Cincel.

Villar Ezcurra, A. (2010, ene.-jun.) El yo inasible de Pascal frente a la fortaleza del sujeto cartesiano. Isegoría, 42, 265-278.

Weisheipl, J. (1984). Friar Tommaso d'Aquino, His Life, Thought and Work. Garden City, N. Y.: Doubleday and Co.

Wittgenstein, L. (1976). Estética, psicoanálisis y religión. Buenos Aires: Sudamericana.

Wittgenstein, L. (1979). Cartas a Russell, Keynes y Moore. Madrid: Taurus.

Wittgenstein, L. (1981). Observaciones. México: Siglo XXI.

Wittgenstein, L. (1985). Comentarios sobre La rama dorada. México: UNAM.

Wittgenstein, L. (1986). Diario filosófico (1914-1916). México: Planeta.

Wright, G. H. Von (1966). Esquema biográfico. En Jordana, R. (Ed.). Las filosofías de Ludwig Wittgenstein. Barcelona: Oikos-Tau. 
Esta obra se imprimió en Grupo Dao Digital Ltda.

Bogotá, Colombia.

2013 
En este libro se cristaliza el interés por la utilización de una hermenéutica analógica en el campo de la filosofía de la religión y la teologia, concretamente de lo que se ha llamado teología fundamental, que tiene mucha cercania con la filosofía. En efecto, abarca lo que antes se consideraba campo de la apologética y de los fundamentos o bases de la teologia en la razón, los preambula fidei, como los llamaba santo Tomás de Aquino. Coincide con lo que los filósofos analíticos Ilaman filosofía de la religión, la cual contiene los temas que antes se trataban en la teología natural o teodicea. 